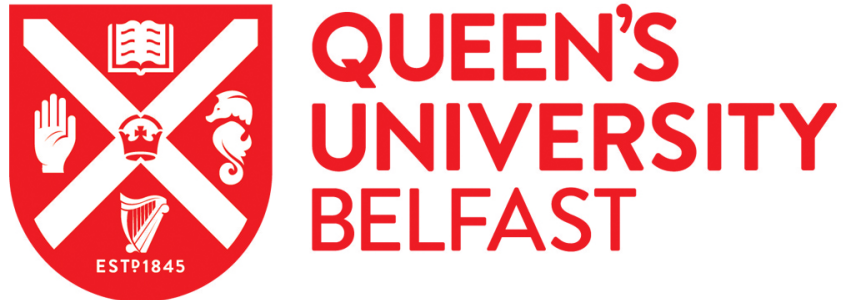

Progress in antennas and propagation for body area networks

Hall, P., Hao, Y., \& Cotton, S. (2010). Progress in antennas and propagation for body area networks. Paper presented at Intl. Symp. on Signals, Systems and Electronics, Nanjing, China.

\section{Document Version:}

Peer reviewed version

Queen's University Belfast - Research Portal:

Link to publication record in Queen's University Belfast Research Portal

\section{Publisher rights}

@ 2015 IEEE. Personal use of this material is permitted. Permission from IEEE must be obtained for all other uses, in any current or future media, including reprinting/republishing this material for advertising or promotional purposes, creating new collective works, for resale or redistribution to servers or lists, or reuse of any copyrighted component of this work in other works.

\section{General rights}

Copyright for the publications made accessible via the Queen's University Belfast Research Portal is retained by the author(s) and / or other copyright owners and it is a condition of accessing these publications that users recognise and abide by the legal requirements associated with these rights.

Take down policy

The Research Portal is Queen's institutional repository that provides access to Queen's research output. Every effort has been made to ensure that content in the Research Portal does not infringe any person's rights, or applicable UK laws. If you discover content in the Research Portal that you believe breaches copyright or violates any law, please contact openaccess@qub.ac.uk. 


\title{
PROGRESS IN ANTENNAS AND PROPAGATION FOR BODY AREA NETWORKS
}

\author{
Hall P S 1 , Hao, $\mathrm{Y}^{2}$ and Cotton, $S \mathrm{~L}^{3}$ \\ ${ }^{1}$ University of Birmingham, UK. \\ p.s.hall@bham.ac.uk \\ ${ }^{2}$ Queen Mary, University of London, UK \\ ${ }^{3}$ Queens University Belfast, UK
}

Keywords: Antennas, radiowave propagation, body centric, communications

\begin{abstract}
Research in antennas and propagation for body centric wireless communications continues to grow, in response to increasing demands for body area networks (BANs) for healthcare, defence and personal communications and entertainment. This paper will briefly review recent international work, and then report on advances in three UK BAN research centres, Birmingham, Queen Mary and Queens Belfast. The demand for greater security in BAN links could be met by the use of $60 \mathrm{GHz}$ channels, and the likely channel characteristics will be discussed and initial results given. New insights into surface wave excitation on the human body has enabled a novel low profile antenna to be designed that maximises link performance where very thin antennas are necessary. Finally advances in the numerical computation are reported, in which the importance of relating phantoms directly to patients to give subject specific simulations and to allow improved modelling of internal organs.
\end{abstract}

\section{Introduction}

The topic of antennas and propagation for body centric wireless communications continues to be of significance, as recent work on sensor networks for a variety of applications, such as healthcare [1,2] and defence [3,4,5] demonstrate. Currently the field of antennas has resolved itself into the following categories, narrow band, wideband, implantable, fabric and multiple antennas. The sensitivity of antenna performance to body proximity and in particular patch antennas working in a variety of modes has been investigated, [6]. The reduced size patches are shown to be equivalent in performance to other types. Size reduction is also shown in cavity slot BAN antennas, [7]. Ultra wideband systems are considered to be potentially useful, and the transient performance of such antennas on the body has been investigated, [8]. There are many publications on implantable antennas, such as a novel chandelier meandered design for ingestible devices, [9], optimised antennas for rat implantation, [10] and the cavity slot, [7]. Fabric antennas are subject to bending and crumpling and this is studied in [11]. Such antennas have been designed for astronauts [12] and rescue workers [13]. Multiple antenna systems for diversity and MIMO, [14] communications shown improved capacity performance over single antenna links. Work in channel modelling continues, with the difficult problem of modelling of non-stationary channels, being addressed in [15] using autoregressive transfer functions. The interest in on-body radiowave propagation has also lead to a renewed interest in propagation mode analysis, [16,17]. Simulation of antennas and propagation on and around the human body throws up major problems relating to scale, and methods such as parallelised FDTD [18] and the equivalence principle, [19], are being studied.

\section{Body Area Network Channels at $60 \mathrm{GHz}$}

There is now interest in investigating the performance of BANs operating at mm wavelengths and in particular $60 \mathrm{GHz}$ and there are two primary reasons for this. Conventionally BANs have used frequencies in the $400 \mathrm{MHz}$ to $3 \mathrm{GHz}$ band, but this band has substantial value for cellular services, and is hence known as the 'Golden Spot'. So moving BANs to high $\mathrm{GHz}$ bands will free space at lower frequencies that can be used elsewhere. In addition, the $\mathrm{mm}$ wave bands have little civil commercial value at present; for example, the spectrum auction of UMTS bands at $1.9 \mathrm{GHz}$ raised $£ 24 \mathrm{bn}$, whereas similar auctions at $30 \mathrm{GHz}$ only raised $£ 30 \mathrm{M}$, and attempts to auction higher bands have failed. BANs are one of the few applications that could make good use of these bands.

Another reason to examine $\mathrm{mm}$ wave bands is that security is now considered to be a paramount requirement for BANs, and uncertainties about it may even be holding back faster deployment. Security can mean that BANs may interfere with other systems, for example ISM band based medical sensor networks in hospitals will have to coexist with other equipment working in these bands. Also there is a fear the outside systems may be able to interfere with BANs, either to deny use or to insert false data; this is again a problem for medical sensor networks. In the defence application programs, such as the Future Infantry Soldier Technology, (FIST), [3], in the UK and Land Warrior, [4], and Future Force Warrior (FFW), [5], in the USA, aim to 
increase user performance by a variety of body worn systems incorporating wireless links for body worn sensors or links to weapons. In this application there is an overriding need to reduce the signature of the demounted soldier to prevent or reduce the chance of enemy detection and subsequent attack.

The $60 \mathrm{GHz}$ band is now being actively considered for personal area network communications, [20, 21]. The primary advantages are small RF components and antennas, high atmospheric attenuation and hence lower interference, visibility and susceptibility to interference, a wide available spectrum $(57-64 \mathrm{GHz})$ and high data rates. Concerns relate to high attenuation leading to low received signal levels and possible high cost. However high gain antennas can be used to offset the channel loss, but can also lead to susceptibility to shadowing. In, for example, an indoor environment, base station to TV link, shadowing due to loss of line of sight as a human stands in the way, can be overcome by switching the antenna to a reflected ray, either off the wall or ceiling. Multipath is present, but the large extra attenuation of the longer reflected rays mean that fading is much less deep than at microwave frequencies, and may be of the order of $20 \mathrm{~dB}$. However fades due to shadowing as noted above can be as deep as 40 to $60 \mathrm{~dB}$, necessitating switched antennas. Data buffering can overcome the finite switching time. These typical indoor characteristics will be present in body area networks, but in general the physical distances are much shorter and body motion will increase the possibility of shadowing. Such high gain antennas also leads to higher security, as the energy would be confined to a vertical cylinder surrounding the body, thus giving good BAN to $\mathrm{BAN}$ and BAN to fixed base station isolation, except when needed, when the BAN antennas would switch to an outward facing beam. This has long been an aspiration for microwave BANs, but the low directivity of small antennas prevent it.

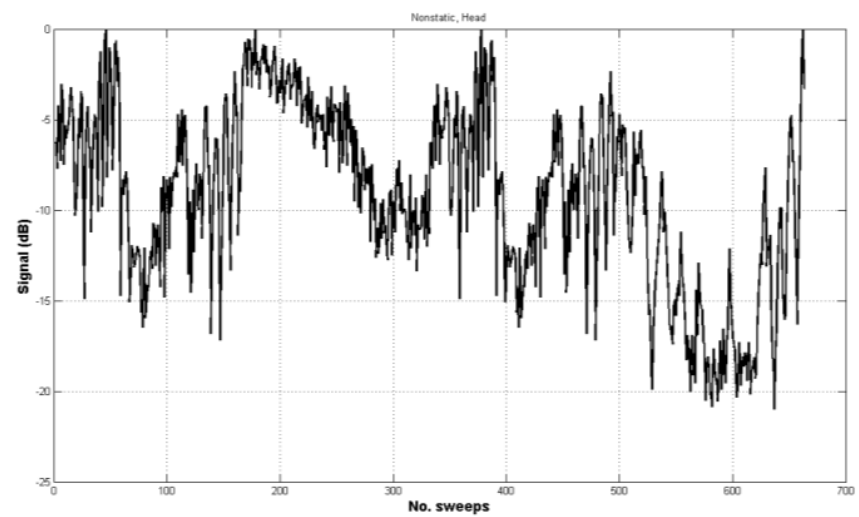

Fig 1 Normalised measured $60 \mathrm{GHz}$ received signal (horn antennas, belt to head channel, random body movement, University of Birmingham)

Measurements, made at the University of Birmingham, of the temporal characteristics of an on-body channel at $60 \mathrm{GHz}$ using horn antennas are shown in Fig 1. Significant fading is evident, due to both multipath and shadowing, and it is hard to differentiate between the two. The very high multipath fading rate means that conventional extraction of fast and slow fading characteristics cannot be done using narrowband data; however as shadowing is likely to be the main contributor, such temporal measurements are widely used in assessing $60 \mathrm{GHz}$ PAN channels, [22]. Wideband channel sounders have been used occasionally to extract fast fading, $[22,23]$, static indoor PAN channels have been characterised extensively, [24], and some studies of body shadowing effects have been done, $[23,25]$. However there is almost no work on the effects of moving base stations or moving humans on 60 $\mathrm{GHz}$ channels.

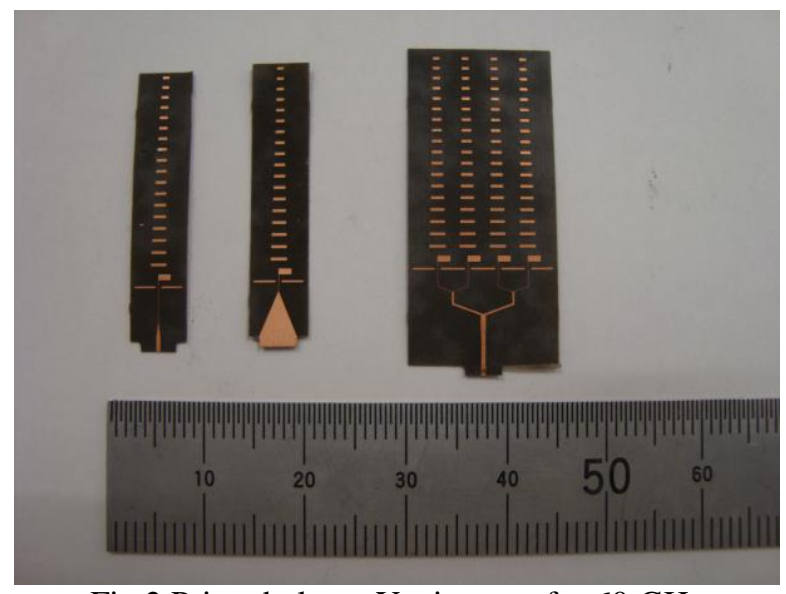

Fig 2 Printed planar Yagi arrays for $60 \mathrm{GHz}$ (University of Birmingham)

Planar high gain antennas at $60 \mathrm{GHz}$ have been designed at the University of Birmingham, both to enable channel measurements to be made into the shadowing region, and to demonstrate possible designs for realistic equipment. One requirement for channel characterisation is that antennas with both polarisations are needed. Fig 2 shows a printed Yagi antenna, which has a polarisation parallel to the substrate, and Fig 3 shows an equivalent made using substrate integrated waveguide (SIW) concepts, which gives polarisation normal to the substrate. Both antennas are made on $0.127 \mathrm{~mm}$ thick RT/Duroid 5880 substrate. Such antennas would be used mounted along the skin surface, spaced by a few millimetres, and pointed in the direction of the channel. Measured gain for both arrays is about $15 \mathrm{dBi}$, and measured $3 \mathrm{~dB}$ beamwidths in E plane and $\mathrm{H}$ plane are about $20^{\circ}$ and $30^{\circ}$ respectively.

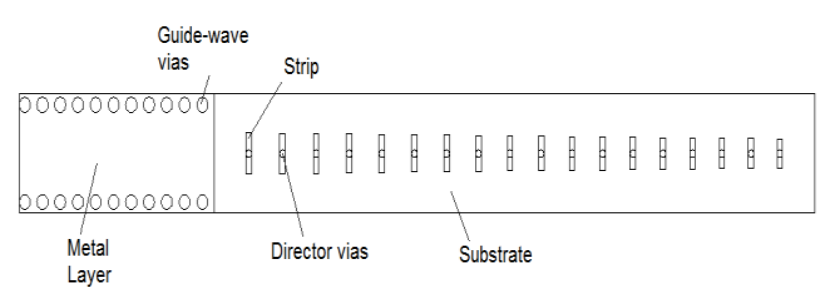

Fig 3 (a) 


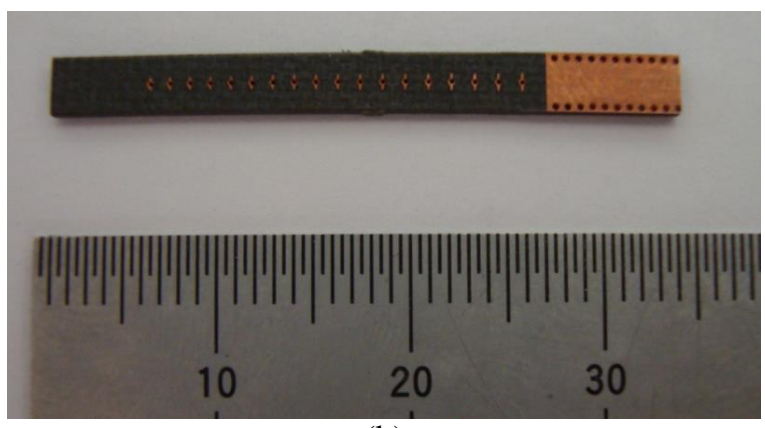

(b)

Fig 3 Substrate Integrated Waveguide array for $60 \mathrm{GHz}$ (a) Configuration, (b) manufactured array

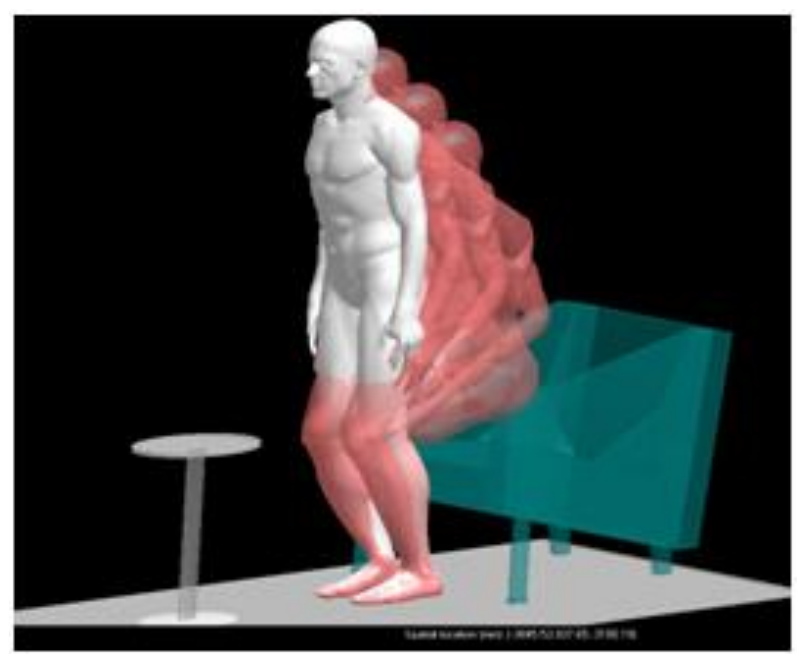

Fig.4: Frames of POSER avatar James during a standing up movement in a real environment (University of Birmingham)

One of the problems of using numerical electromagnetics with the human body is that of combining body movement with the EM simulator. The University of Birmingham have shown that animation software, such as POSER, could provide realistic phantoms shapes, that could then be used frame by frame in the simulator, [27]. Fig 4 shows frames as the POSER avatar James stands up from a sitting position. At $2.45 \mathrm{GHz}$ good agreement is obtained with measured channel data using the avatar as a homogeneous phantom. A finite element solver, XFDTD is used. At $60 \mathrm{GHz}$ a finite element or finite difference approach would present difficulties due to the high level of computational intensity. For this reason, Queens University, Belfast, have used a ray tracing method.

The characteristics of $60 \mathrm{GHz}$ communications channels between soldiers in the field has recently been studied, using ray launching with geometrical optics $(\mathrm{GO})$ and the uniform theory of diffraction (UTD), by Queens University, Belfast, [26]. The simulations followed stages of a cordon and sweep type operation, and modelled bidirectional signal propagation between a squad of four US infantry troops. Fig 5 shows four frames from an animation of the troops entering a building. The dynamic transmission channel simulations used a full 3-

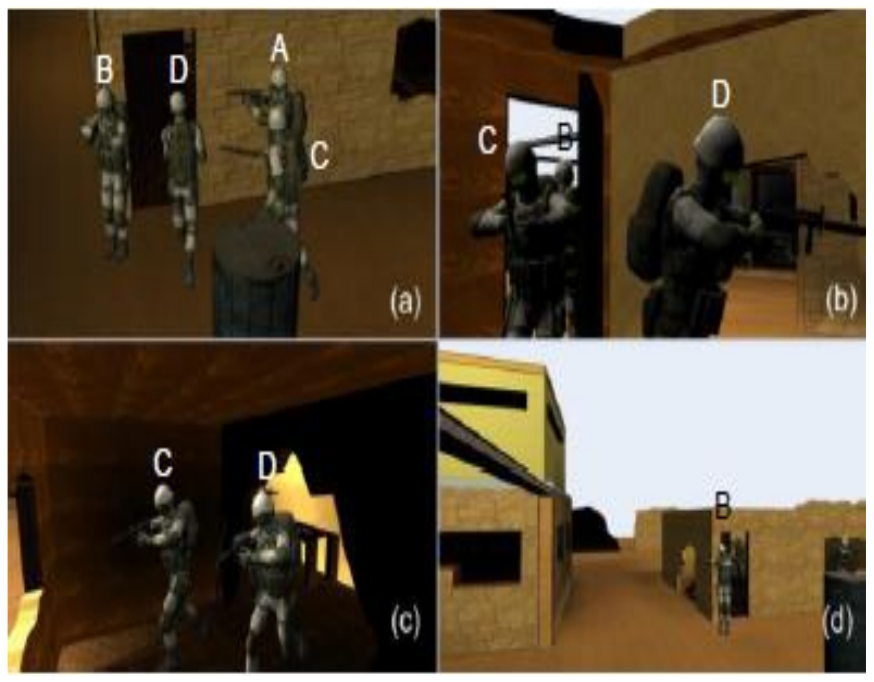

Fig. 5 Sample of key frames of animation: (a) start position, (b) soldiers $\mathrm{C}$ and $\mathrm{D}$ entering building, (c) soldier $\mathrm{C}$ and $\mathrm{D}$ clearing front room, and (d) end position. (Queens University, Belfast)

D ray-launching algorithm that was set to calculate all reflections, penetrations and diffractions. The animations were performed at a rate of 50 frames per second, which for the purposes of ray launching simulation is analogous to 50 samples of the mm-wave channel per second.

Data processing has been done to extract statistics relating to angle of arrival, and time of arrival. Three cases have been considered, soldiers in the open, entering a building and moving about within a building. For stage 1 , in the open, the azimuth rms angle spread had a 90 percent probability of being less than $90^{\circ}$. The corresponding figure for the elevation rms angle spread was lower at $20^{\circ}$, an observation most likely to have been caused by the fact that each of the soldiers were of the same height and were vertically upright. For stages 2, entering a building, and 3, moving within the building, rms angle spread for both azimuth and elevation planes were increased. This increase within indoor environments may be due to the larger number of multipath components caused by the close proximity of scattering and reflecting objects such as walls, ceilings, and furniture.

The power delay profile, (PDP), has also been extracted. In the open, the vast majority of the energy is contained within the direct path which typically arrives within $25 \mathrm{~ns}$, and occasionally significant multipath components which arrive between 100 and $150 \mathrm{~ns}$. It can be seen that the vast majority of the signal energy is made up of very few multipath components, and arrives with very little delay. Within the building multipath is much more significant. 


\section{Planar Surface Wave Antenna}

The increased interest in wireless channels on the body has lead to a review of the types of propagation mode that may occur on the body, [28]. Clearly, energy may propagate in a surface wave, creeping wave or space wave. Much work has previously done on coupling to the surface wave by HF antennas situated on the earth, [29]. Although the properties of the human body are similar to those of the earth, there are differences in detail. The dominant form of the surface wave is a TM mode, which has electric fields both vertical to the surface and in the direction of propagation. It is also well known that antennas with strong currents in the vertical direction, such as the monopole and to a lesser extent the PIFA and patch, will give good channel performance on the human body. However there are cases where flat profile antennas would be desirable, such as when integrated with a sticking plaster type of sensor, [29]. This has lead to an investigation at the University of Birmingham into the design

(a) $\mathrm{E}_{\mathrm{x}}$

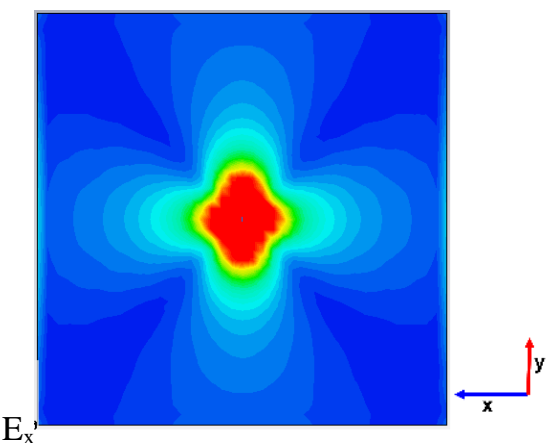

(b)

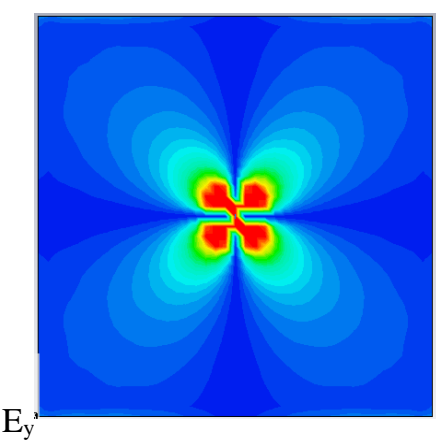

(c) $E_{z}$

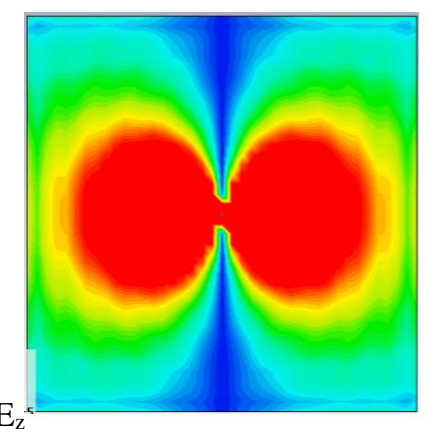

Fig 6 Near electric field distribution of $X$ oriented small dipole $5 \mathrm{~mm}$ above muscle phantom at $2.45 \mathrm{GHz}$ (University of Birmingham)

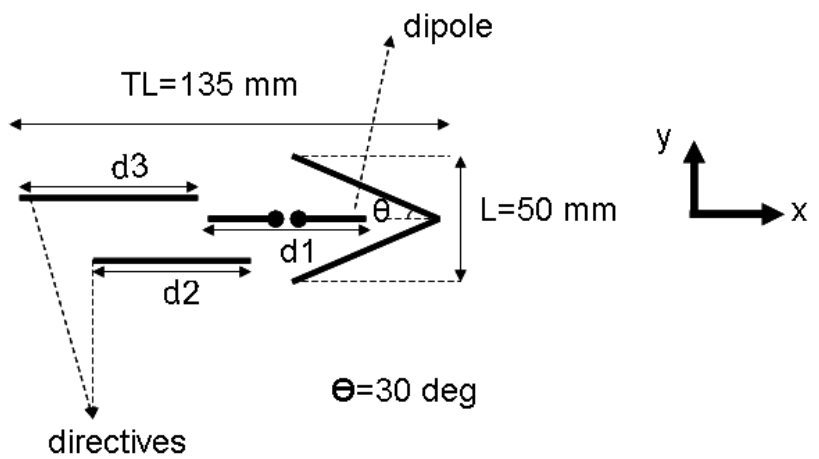

Fig. 7 Surface wave Yagi antenna: $d_{1}=50 \mathrm{~mm}, \mathrm{~d}_{2}=60$ $\mathrm{mm}, \mathrm{d}_{3}=55 \mathrm{~mm}$

(University of Birmingham)

of antennas with currents in the plane of the surface of the body, [30,31].

Fig 6 shows the near fields of a short dipole close to the surface of a muscle phantom of size, $600 * 600 * 50 \mathrm{~mm}^{3}$, having $\varepsilon_{\mathrm{r}}=52.7, \sigma=1.77 \mathrm{~s} / \mathrm{m}$. The dipole is $2 \mathrm{~mm}$ long and is oriented in the $\mathrm{X}$ direction and Fig 6a indicates that this is in the horizontal direction on the page. It can be seen in Fig 6c that the $\mathrm{E}_{\mathrm{z}}$ component is strongest, and has nulls in the $\mathrm{Y}$ direction and lobes in the $\mathrm{X}$ direction. The nulls might be expected in the $\mathrm{Y}$ direction as a dipole in free space has no $\mathrm{E}_{z}$ field in this direction. There are strong $E_{z}$ fields in the $X$ direction, in addition to $E_{x}$ fields, which suggest that there may be strong coupling to the TE surface wave mode.

The strong coupling to the Norton type surface wave has been established through simulations of the $S_{21}$ parameter between two small dipoles in various orientations, $5 \mathrm{~mm}$ above a muscle phantom. Whilst the $S_{21}$ is strongest for $\mathrm{Z}$ oriented dipoles, there is useful transmission of energy when the two dipoles are $\mathrm{X}$ oriented. This then suggested that this transmission could be increased by using a Yagi array concept to increase the directivity of the antenna along the body surface. Fig 7 shows the novel surface wave Yagi array, having two directors and two reflectors. The positions of the directors and reflectors have been partially optimized to

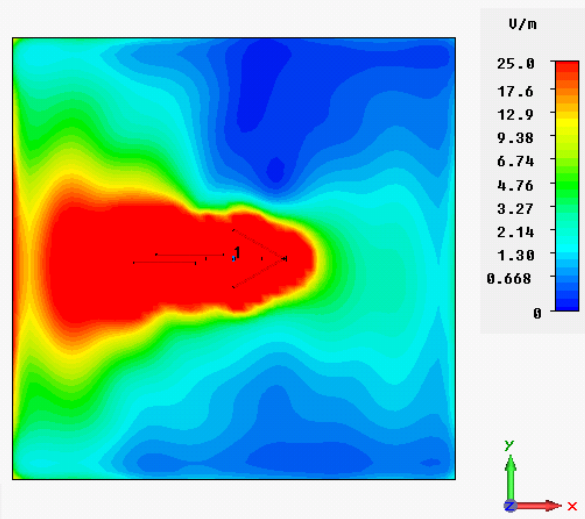

Fig 8 Electric field distribution $\left(E_{z}\right)$ of surface wave Yagi antenna $5 \mathrm{~mm}$ above muscle phantom at $2.45 \mathrm{GHz}$ (University of Birmingham) 
demonstrate the potential of such configurations.

Fig 8 shows the $E_{z}$ near field distribution of the surface wave Yagi array $5 \mathrm{~mm}$ above the muscle phantom, with the Yagi oriented in the $-\mathrm{X}$ direction as in Fig 7. It is clear that there a considerable increase in the energy directed by the Yagi which also has a significant front to back ratio. The far field radiation pattern indicate that the main beam of the array is oriented about 30 deg above the surface, but at higher elevations there is some reduction of power radiated away from the surface. The simulated performance of a pair of such arrays shows that the $S_{21}$ is similar to a pair of small dipoles oriented in the $\mathrm{Z}$ direction, that is vertical to the muscle surface.

The performance of the array depends on the material properties, and is surface wave coupling is less strong on fat tissue, which has lower permittivity and loss. Work is underway at the University of Birmingham to fabricate the antenna.

\section{Subject Specific Propagation Studies}

Studies of the variations in on-body and in-body propagation has recently been undertaken by Queen Mary, University of London. Nine subjects having the body parameters, shown in Table 1 , have been scanned using a magnetic resonance imager (MRI), and the data collected was used to create a set of phantoms. Body mass index of the set range from 19 to 27 , representing slim to well-built.

Table 1

Dimensions of nine subjects scanned using MRI and used in FDTD simulations

( $\mathrm{F}$ - female, $\mathrm{M}$ - male)

\begin{tabular}{|l|c|c|c|c|c|}
\hline & $\begin{array}{l}\text { Height } \\
(\mathbf{m})\end{array}$ & $\begin{array}{l}\text { Weight } \\
(\mathbf{k g})\end{array}$ & BMI & $\begin{array}{l}\text { Waist } \\
(\mathbf{c m})\end{array}$ & $\begin{array}{l}\text { Chest } \\
(\mathbf{c m})\end{array}$ \\
\hline F01 & 1.60 & 50 & 19.5 & 67.0 & 79.4 \\
\hline F02 & 1.66 & 55 & 20.0 & 72.7 & 85.6 \\
\hline F03 & 1.55 & 52 & 21.6 & 68.8 & 96.9 \\
\hline F04 & 1.65 & 52 & 19.1 & 66.2 & 80.7 \\
\hline F05 & 1.80 & 75 & 23.1 & 81.9 & 107.9 \\
\hline M01 & 1.76 & 73 & 23.6 & 82.6 & 91.3 \\
\hline M02 & 1.67 & 56 & 20.1 & 67.1 & 82.1 \\
\hline M03 & 1.78 & 87 & 27.5 & 91.0 & 101.1 \\
\hline M04 & 1.80 & 85 & 26.2 & 84.2 & 98.4 \\
\hline
\end{tabular}

The derived phantoms were them used to simulate channels with the transmitter on the front and receivers on the back and the front. A patch antenna designed to operate at 2.4 $\mathrm{GHz}$ was used as the transmitting antenna in FDTD simulations, [32]. The antenna was first simulated using CST Microwave Studio ${ }^{\mathrm{TM}}$, and the radiation patterns were extracted and converted to surface currents used as excitations in FDTD simulations. The antenna was mounted on the left waist of the subjects. In the parallel FDTD algorithm, the whole simulation domain was divided into four, five, and five sub-domains along $x$-, $y$-, and $z$-directions, respectively. Each simulation lasted around 1.5 hours. Simulation and measured

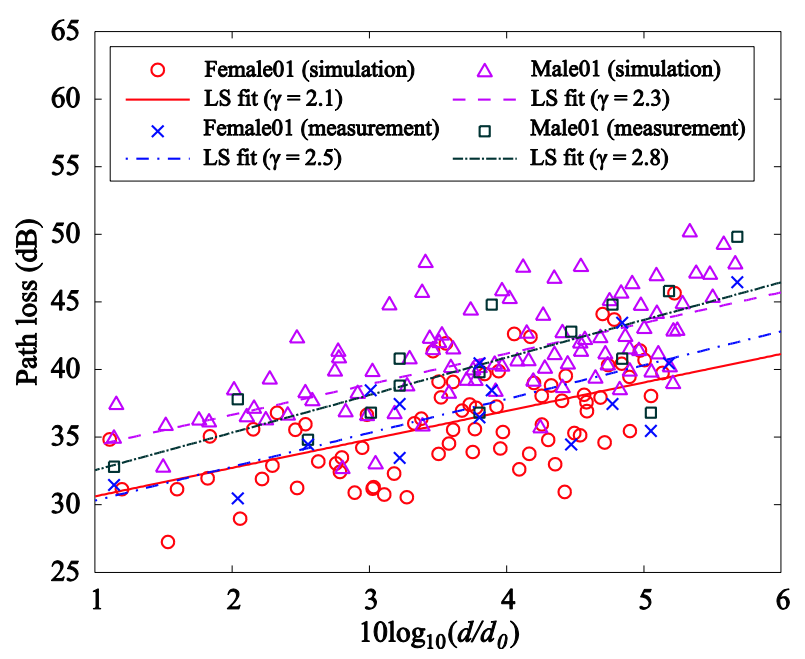

Fig. 9 Path loss against distance for subjects Female01 and Male01 in on-body radio channels.

(Queen Mary, University of London)

results of channel path loss against distance are shown in Fig 9 for a male and female. Least-squares fitting is used to extract the path loss exponent. There is reasonable agreement between the exponents for the same subject. The typical variation of exponent across the whole subject set is from 2.1 to 2.9 for the front channels and 2.4 to 3.4 for the back ones, where the greater exponent is expected due to the non line of sight in the front to back channel. The parallel FDTD code allows simulation of very large problems. Fig 10 shows a typical medical scene in which a doctor treats a patient lying on a bed.

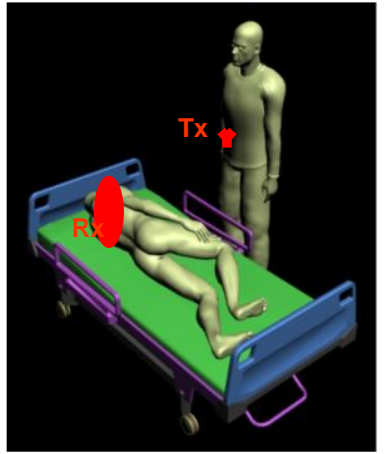

(a)

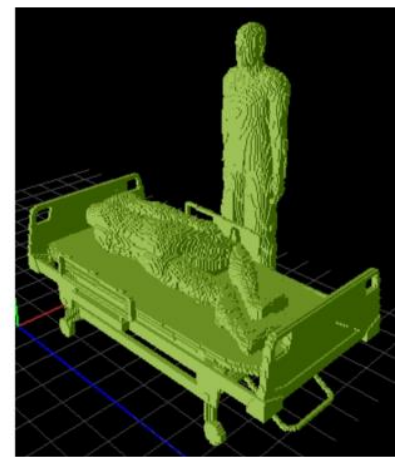

(b)
Fig 10 Simulation of medical scene with patient on bed and doctor standing

(a - in animation scene, b - in FDTD software) (Queen Mary, University of London) 


\section{Implant Channel Simulation}

Various types of implanted antenna for different placements have been designed [33]-[36]. Communication protocols between implant devices and base stations have been studied [37]. One of the most important issues is the reliability of the communication link between the implant and off-body base station. To design a reliable link, knowledge about the propagation channel model is necessary. There is some work in which in-body to off-body path loss has been modelled, [38, 39]. Sani et. al. have calculated the link budget for communication between implant and off-body base station [40]. The propagation channel between a cardiac implanted loop antenna and an off-body base station has recently been simulated at the University of Birmingham. The antenna is simulated inside a digital male phantom using XFDTD software (Remcom Inc.), and the pattern is shown in Fig 11. The frequency band is $403 \mathrm{MHz}$ that has been allocated for medical implanted communication services (MICS) applications [41]. In this scenario, a transmitter is placed in one corner of a $5 \mathrm{~m}$ by $5 \mathrm{~m}$ room and the body performs a random walk movement inside the room, as shown in Fig 12. A ray tracing method is used for calculating the received power. Once the radiation pattern is calculated, it is used in each step of the walk, with appropriate position from the base station and orientation. The reflections from the walls, floor and ceilings are summed with the direct ray and a time series of received signal of 5000 points is calculated. Many standard distributions were examined in attempt to fit with the simulation results. As shown in Fig. 13, a log-logistic model shows the best fitting. Since the ray-tracing is not a perfect method for indoor channel modelling at this

frequency, due to the base station being in the near field of the antenna in the body, the error in the method is estimated. Results show that for small values of electric field intensity, the error is high. However, for larger values of electric field intensity that occurs more frequently, the error of this method is below $6 \mathrm{~dB}$.

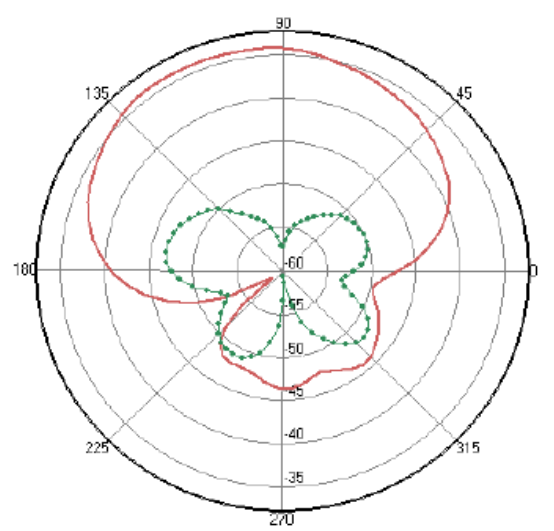

Fig 11 Radiation pattern in horizontal plane of cardiac implant antenna in male human phantom at $403 \mathrm{MHz}$

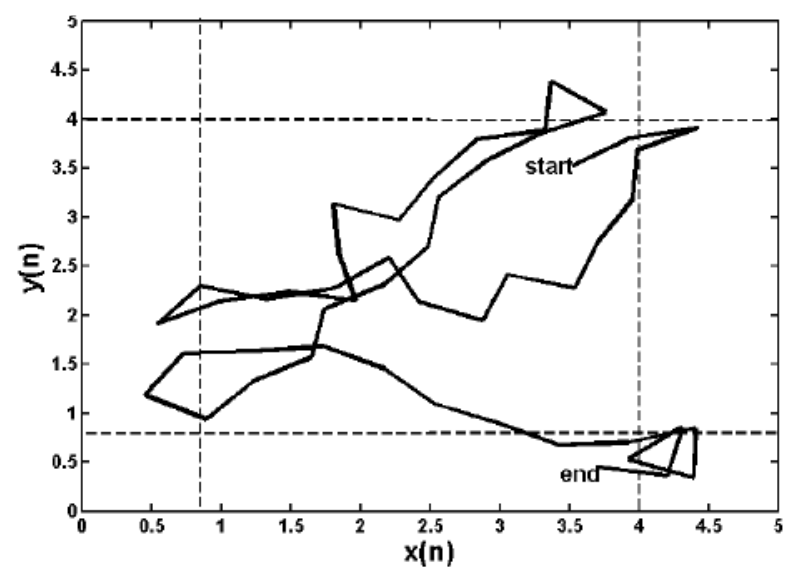

Fig 12 Random walk used for implant to base station channel

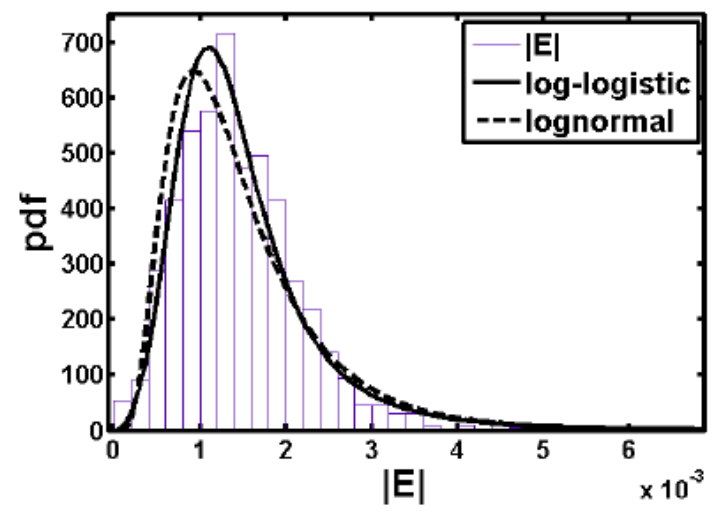

Fig 13 Statistical model for implant to base station channel at $403 \mathrm{MHz}$

\section{Conclusions}

This paper has briefly reviewed the current state of research into antennas and propagation for body centric wireless communications and described three recent developments. There is growing interest in channels at 60 $\mathrm{GHz}$, where low levels of interference and observability will occur but channels will experience deep fading due to relatively low diffraction around the body. A novel low profile antenna is presented that excites the surface wave on a ground having the same parameters as the human body. Finally new work relating to numerical simulation is discussed.

\section{Acknowledgements}

This work is funded in part by EPSRC, UK, grant ref (EP/E029922/1).

\section{References}

1. El Helw M, Pansiot J, Mcllwraith D, Ali R, Lo B, Atallah L, "An integrated multi-sensing framework for pervasive healthcare monitoring", 3rd Int Conf on Pervasive Computing Tech for Healthcare, 1-3 April 2009, pp 1 - 7 
2. Scanlon, W.G. Conway, G.A. Cotton, S.L. "Antennas, propagation considerations for robust wireless comms in medical body area networks", IET Seminar on Ant and Prop for BodyCentric Wireless Comms, April 2007, pp 37-37

3. http://www.army-technology.com/projects/fist/Cox

4. M, "Troops in Iraq give thumbs up to Land Warrior", www.armytimes.com, Jun 26, 2007.

5. "Future Force Warrior (FFW) Tech Demonstration", Defence Update, Int Online Defence Mag, 2006, 2

6. Cotton, S.L.; Scanlon, W.G.; "Channel Characterization for Single- and Multiple-Antenna Wearable Systems Used for Indoor Body-to-Body Communications", IEEE Trans AP, Vol 57, No 4, Part 1, April 2009, pp $980-990$

7. Wei X, Saito K, Takahashi M, Ito K "Performances of an Implanted Cavity Slot Embedded in the Human Arm", IEEE Trans AP, Vol 57, No 4, Part 1, April 2009, pp $894-899$

8. Alomainy A, Sani A, Rahman A, Santas J G, Hao Y, "Transient Characteristics of Wearable Antennas and Radio Propagation Channels for UWB Body-Centric Wireless Comms", IEEE Trans AP, Vol 57, No 4, Part 1, April 2009, pp 875 - 884

9. Izdebski $\mathrm{P}$ and Rahmat-Samii Y., "Antenna design for medical biotelemetry applications: small antennas for ingestible capsules," Dig. URSI-USNC National Radio Science Meeting, Boulder, CO, Jan. 3-6, 2008.

10. Karacolak T, Cooper R, Topsakal E, "Electrical Properties of Rat Skin and Design of Implantable Ants for Medical Wireless Telemetry", IEEE Trans AP, Vol 57, No 9, Sept. 2009, pp 2806 2812

11. Bai Q, Langley R, "Wearable EBG antenna bending and crumpling", Loughborough Antennas \& Propagation Conference, 16-17 Nov. 2009, pp 201-204

12. Kennedy T F, Fink P W, Chu AW, Champagne N J, Lin GY, Khayat M A, "Body-Worn E-Textile Antennas: The Good, the Low-Mass, and the Conformal", IEEE Trans AP, Vol 57, No 4, Part 1, April 2009, pp $910-918$

13. Vallozzi L, Rogier H, Hertleer C, "A textile patch antenna with dual polarization for rescue workers' garments", 3rd European Conf on Ant and Prop, March 2009, pp1018 - 1021

14. Khan I and Hall P S, "Experimental Evaluation of MIMO Capacity and Correlation for Narrowband Body-Centric Channels" IEEE Trans AP, Vol 58, No 1, 2010, pp 195 - 202

15. Cotton, S.L.; Conway, G.A.; Scanlon, W.G.; "A TimeDomain Approach to the Analysis and Modeling of On-Body Propagation Using Synchronized Measurements at $2.45 \mathrm{GHz}$, IEEE Trans AP , Vol 57, No 4, Part: 1, 2009 , pp 943 - 955

16. Sasamori, T.; Takahashi, M.; Uno, T.; "Transmission Mechanism of Wearable Device for On-Body Communications", IEEE Trans AP, Vol 57 , No 4, Part: 1, 2009 , pp 936 - 942

17. Vaughan R G, et al, "Theory of Propagation for Direct OnBody Wireless Comms", 2nd IET Seminar on Ant and Prop for Body-Centric Comms, London, UK, April 2009, pp.1-5

18. Bringuier, J.N.; Mittra, R.; Wiart, J.; "Efficient Modeling of Body Area Networks using the Parallized FDTD", 2nd European Conference on Antennas and Propagation, Edinburg, UK,11-16 Nov. 2007, pp 1 - 5

19. Sani, A.; Yan Zhao; Yang Hao; Alomainy, A.; Parini, C.; "An Efficient FDTD Algorithm Based on the Equivalence Principle for Analyzing Onbody Antenna Performance", IEEE Trans AP, Vol 57 , No 4 , Part: 1, 2009 , pp 1006-1014

20. Smulders, P "Exploiting $60 \mathrm{GHz}$ band for local wireless multimedia access", IEEE Comms Mag, 40,1, pp 140-147, Jan 2002. 21. Guo N, et al "60-GHz MM-Wave Radio: Principles, Techs, and New Results," EURASIP Jnl on Wireless Comms and Nets ,1, pp. $48-48$, Jan 2007.
22. Moraitis, N. et al, "Indoor channel measurements and characterization at $60 \mathrm{GHz}$ for local area network applications", IEEE Trans AP, 52, 12, pp 3180- 3189, Dec. 2004.

23. Zwick, T. et al, "Wideband Channel Sounder With Measurements and Model for the $60 \mathrm{GHz}$ Indoor Radio Channel", IEEE Trans on Vehicular Tech, 54, 4, pp: 1266- 1277, 2005.

24. IEEE P802.15, Wireless Personal Area Networks, TG3c Channel Modelling Sub-Committee Final Report, March 2007, (IEEE 15-07-0584-01-003c)

25. Collonge, $\mathrm{S}$ et al, "Influence of the human activity on wide-band characteristics of the $60 \mathrm{GHz}$ indoor radio channel", IEEE Trans on Wireless Comms, 3, 6 pp 2396- 2406, Nov. 2004.

26. Cotton S L, Scanlon W G, Madahar B K, "Simulation of Millimetre-Wave Channels for Short-Range Body-to-Body Communications", European Conference on Ant and Prop, Barcelona, Spain, EuCAP, 12-16 April 2010

27. Gallo M, Hall P S, Bai Q, Nechayev Y I, Constantinou C $\mathrm{C}$, and Bozzetti M, "Simulation and Measurement of Dynamic OnBody Communication Channels", IEEE Trans Ant \& Prop, accepted for publication

28. Norton K. A. "The Physical Reality of Space and Surface Waves in the Radiation Filed of Radio Antennas," Proceedings of the Institute of Radio Engineers, Vol 25, No.9, pp. 1192-1202, Sept 1937

29. Kellomaki, T.; Whittow, W.G.; Heikkinen, J.; Kettunen, L. "2.4 GHz plaster antennas for health monitoring", 3rd European Conference on Antennas and Propagation, Berlin, Germany, 23-27 March 2009, pp211 - 215

30. Akhoondzadeh-Asl L, Hall P. S., Nechayev Y., "Wave Excitation on Human Body by a Short Dipole", $4^{\text {th }}$ European Conference on Ant and Prop, Barcelona, Spain, 2010

31. Akhoondzadeh-Asl L, Hall P. S., Nechayev Y, "Novel Conformal Surface Wave Yagi Antenna for On-Body Communication Channel”, IEEE AP-S Int Symp, Toroto, Canada, July, 2010

32. A. Sani, Y. Zhao, Y. Hao, "Analysis of on-body antenna radiation pattern using a numerical technique based on equivalence principle and FDTD," Loughborough Antenna and Propagation Conference (LAPC '08), Loughborough, 17-18 March 2008.

33. Y. Rahmat-Samii and J. Kim, Implanted Antennas in Medical Wireless Communications, 1st ed., United States of America, Morgan \& Claypool, 2006.

34. F. Merli, L. Bolomey, E. Meurville, and A. K. Skrivervik, "Implanted antenna for biomedical applications," in Proc. AP-S, 2008, pp. 1-4.

35. T. Houzen, M. Takahashi, K. Saito, and K. Ito, "Implanted planar inverted F-antenna for cardiac pacemaker," in Proc. IWAT, 2008 , paper 220, p. 346.

36. K. Ito, W. Xia, M. Takahashi, and K. Saito, "An implanted cavity slot antenna for medical communication systems," in Proc. EUCAP, 2009,pp. 718-721.

37. M. L. Manwaring, k. L. Jones, and K. H. Manwaring, "Issues in developing a communication protocol for wireless (implanted) biodevices," in Proc. Ninth IEEE Symp. ComputerBased Medical Systems, 1996, pp.65-70.

38. K. Sayrafian-Pour, W.B. Yang, J. Hagedron, J. Terrill, and K. Y. Yazdandoost, "A statistical path loss model for medical implant communication channels," in Proc. PIMRC, 2009, pp. 29952999.

39. Wireless Personal Area Network, IEEE Std. 802.15, 2009.

40. Sani, A. Alomainy, and Y. Hao, "Numerical characterization and link budget evaluation of wireless implants considering different digital human phantoms," IEEE. Trans. Microwave Theory Tech., vol. 57, No.10, pp. 2605-2613, Oct. 2009. 41. FCC Rules and Regulations, "MICS Band Plan," Jan. 2003. 